\title{
OLHARES SOBRE A CIDADE: UM OLHAR SOBRE O CASARIO ANTIGO DE CACHOEIRO DE ITAPEMIRIM
}

\section{PERSPECTIVES ON THE CITY: A LOOK AT THE OLD HOUSES OF CACHOEIRO DE ITAPEMIRIM}

RESUMO: Este artigo objetiva apresentar os resultados de uma proposta de trabalho desenvolvida com alguns alunos do curso de História do Centro Universitário São Camilo - Espírito Santo. Trata-se de uma pesquisa sobre o casario antigo da cidade de Cachoeiro de Itapemirim, sul do Espírito Santo, em que se utilizou tanto a história oral quanto o registro fotográfico, numa tentativa de construir um pouco da identidade cachoeirense considerando as maneiras de morar de seus habitantes. Entre os resultados encontrados com a realização desse trabalho, destaca-se a descoberta de diversos documentos que retratam um pouco do cotidiano da cidade e de seus moradores.

Palavras-chave: Casario antigo. Cachoeiro de Itapemirim. História oral.

\begin{abstract}
This article aims to present the results of a work proposal developed with some students of History course on São Camilo University Center - Espírito Santo. This is a survey of the old houses in the city of Cachoeiro de Itapemirim, south Espírito Santo, which used both oral history and the photographic record in an attempt to build a bit of cachoeirense identity from the ways of its inhabitants' living. Among the results found with the completion of this work, there is the discovery of various documents that depict some of the city's daily life and its residents.
\end{abstract}

Keywords: Old houses. Cachoeiro de Itapemirim. Oral history

\footnotetext{
${ }_{1}$ Professor de História do Instituto Federal do Espírito Santo (UFES)
} 


\section{Introdução}

A cidade de Cachoeiro de Itapemirim, localizada no sul do estado do Espírito Santo, destaca-se por ser a mais importante cidade dessa região do ponto de vista econômico, status construído a partir do fim do século XIX, em decorrência da expansão cafeeira. Em Cachoeiro, havia um porto que recebia todo o café produzido na região sul, uma vez que se localizava no último trecho navegável do rio Itapemirim. O café possibilitou a construção de vias de comunicação, especialmente a via férrea, a primeira da província, da luz elétrica, a primeira do estado, e de outros símbolos do "progresso" em plena expansão capitalista, além de incrementos na área de urbanização.

O nome da cidade deriva de um aspecto geográfico: os cachoeiros ou as cachoeiras do rio Itapemirim, rio que corta a cidade. Por causa desse aspecto geográfico, a cidade, como muitas outras do Brasil, desenvolveu-se econômica e urbanisticamente a partir do rio, do que, hoje, é a região central para a periferia e, por isso, tal região e as áreas próximas são as mais antigas da cidade. Em consequência disso, são essas áreas as que preservam o maior número de casas antigas.

Em que condições se encontram essas casas? De que maneira o historiador pode contribuir para a construção de uma memória social? Foi para responder a essas e a outras questões que, a partir de 2012, desenvolveu-se, juntamente com os alunos do curso de História do Centro Universitário São Camilo - Espírito Santo, uma atividade de pesquisa denominada "Olhares sobre a cidade".

Essa atividade objetivava compreender um pouco da história cachoeirense e sul capixaba por meio das maneiras de morar de seus habitantes, bem como construir uma memória do casario antigo, muitos em estado de demolição pela ação do tempo ou pelas demandas do "progresso". Denominou-se "Olhares sobre a cidade" porque centrou-se no olhar do aluno-historiador, em sua visão e percepção, em sua maneira de captar o mundo, e esse olhar arguto não se limitou ao exterior das casas e de suas fachadas, mas revelou seu interior, desvendou segredos desconhecidos aos olhares desatentos e forneceu detalhes da intimidade de seus habitantes. 


\section{O estudo do meio como possibilidade de pesquisa}

Trata-se de um trabalho de campo também denominado por alguns de estudo do meio e, de acordo com Martins (2009), professores e estudantes podem planejar e realizar trabalhos de campo, isto é, podem percorrer sua cidade ou região com olhos e ouvidos atentos. Assim, poderão encontrar elementos indicativos de permanências e sobrevivências seculares, observáveis diretamente, que configuram realidades de longa duração, capazes de ensejar a iluminação recíproca de passado e presente. Para esse autor, tais

[...] sobrevivências podem ser atividades econômicas, relações sociais e práticas culturais marcadas por enorme longevidade, que ainda conservam parte expressiva de sua "lógica antiga": construções, equipamentos, utensílios, comidas, brinquedos, remédios, modos de fazer, de celebrar e de pensar. Professor e estudantes devem fazer 0 registro iconográfico dessas sobrevivências e colher depoimentos orais a respeito delas (MARTINS, 2009, p. 147).

Vale ressaltar que esse tipo de trabalho vem ao encontro das demandas da história regional e local, pois vivemos um momento em que as pessoas se encontram tão submetidas às tensões da sociedade global, que o regional e o local urgem como forma de resistência a essas tensões. Martins (2009, p.139) argumenta que "[...] as pessoas e os grupos sociais, submetidos às tensões da "sociedade global" [...], experimentam uma "perda de direção". Por isso, os indivíduos buscam um lugar de referência, de símbolos de permanências que respondam às demandas individuais e coletivas por segurança e pertencimento.

Outro aspecto que deve ser destacado é que o estudo do meio possibilita uma reflexão importante sobre a questão da memória. Isso porque, além de inventariar as casas, caracterizá-las do ponto de vista arquitetônico, também oferece oportunidades de uma ausculta profunda à medida que se ouve o morador, fazendo-se uso da história oral. Esse morador torna-se uma fonte de pesquisa e abre seus valiosos arquivos pessoais, que contam parte da memória da família, mas também de uma memória coletiva. De acordo com Fonseca (2009, p.125)

[...)]o ensinar e o aprender História não é algo externo, a ser 
proposto e difundido com uma metodologia específica, mas sim algo a ser construído no diálogo, na experiência cotidiana de forma ativa e crítica. A memória das pessoas, da localidade, dos trabalhos, das profissões, das festas, dos costumes, da cultura, das práticas políticas está viva entre nós. Nós, professores, temos o papel de junto com os alunos auscultar o pulsar da comunidade, registrá-lo, produzir reflexões e transmiti-lo a outros.

Auscultar o pulsar da comunidade e produzir reflexões significa ouvi-la, e a história oral apresenta-se como uma importante ferramenta para esse trabalho. Por isso, uma das etapas desse trabalho foi a história oral, que descortinou realidades da vida privada dos moradores até então desconhecidos, como, por exemplo, histórias de amor entre pessoas de classes e etnias diferentes que, na época, representaram quebra de tabus; mobiliários do início do século XX e suas histórias; histórias de imigrações europeia e asiática; árvores genealógicas de muitas gerações; fotografias de família com valor afetivo e histórico inestimáveis etc.

Para Bittencourt (2009, p.278-279),

O entendimento de que "todo meio é histórico" representa, para os professores de História, noção fundamental e determinante na escolha dos espaços para a realização de um estudo do meio. $O$ importante é saber explorar historicamente qualquer "lugar", fazer um direcionamento do "olhar" do aluno, levando-o a entender o que são fontes históricas não escritas: as construções, os telhados das casas, o planejamento urbano, as plantações, os instrumentos de trabalho, as informações obtidas pela memória oral de pessoas comuns. As marcas do passado são as fontes históricas que se transformam em material de estudo.

É interessante notar que esse trabalho mudou também a visão dos alunos que com ele estiveram envolvidos. Seus depoimentos mostraram o quanto perscrutaram o cotidiano dos moradores, como interagiram com eles, como levaram a sério a proposta e como sua visão a respeito das fontes foi ampliada, pois "Ao se pensar nessa perspectiva, por guardarem vestígios deixados pelo homem ao longo do tempo, também são consideradas fontes: [...] edificações, mobiliário e vestuário, além de outros objetos produzidos ou preservados (ferramentas, utensílios domésticos, peças de decoração etc.), considerados fontes materiais" (BERUTTI \& MARQUES, 2009, p. 59).

Não obstante isso, dar oportunidades para um trabalho de campo como 
esse possibilita também uma ampliação do conceito de memória, que está para além daquela ideia de algo estático, desgastado, ligado ao passado, ou da memória como mecanismo de retenção, definida, ou que precisa ser resgatada. Pelo contrário, como afirma Meneses (1992), ela é um processo contínuo de construção e reconstrução, porque "A elaboração da memória se dá no presente e para responder a solicitações do presente" (MENESES, 1992, p. 11).

\section{Sobre os resultados do trabalho}

Para Perrot (1991), a casa está para além de uma simples construção: é o fundamento material da família e pilar da ordem social; é um elemento de fixação, é propriedade, investimento e pode ser inventariada, partilhada, disputada; é ponto de encontro da família. É, ainda, segundo a mesma autora,

o território em que os proprietários tentam se apropriar da natureza pela exuberância dos jardins e estufas, onde as estações são abolidas, a arte pelo acúmulo de coleções ou pelos concertos privados, o tempo pelas lembranças de família ou de viagens, o espaço pelos livros que descrevem o planeta e pelas revistas ilustradas (...). A leitura, exploração sedentária, é uma maneira de apropriar-se do universo ao torná-lo legível e, por meio da foto, visível. A biblioteca abre o mundo para o mundo; encerra o mundo dentro da casa. (...). (PERROT, 1990, p. 309)

Para captar um pouco dessas questões que Michelle Perrot nos mostra, a atividade dividiu-se nas seguintes etapas²: primeira, a parte fotográfica, em que

2 Para o desenvolvimento do trabalho, elaborou-se o seguinte roteiro:

10 - Divisão da sala em trios, que deverão se reunir para fechar os combinados a respeito do trabalho.

$2^{0}$ - Sorteio das ruas do município que ficarão a cargo de cada grupo.

30 - Leitura da bibliografia indicada, que servirá de fundamentação teórica para o trabalho.

40- Produção de um roteiro de trabalho (planejamento) para organizá-lo e torná-lo viável.

50- Sobre o trabalho em si:

a) Consulta ao proprietário e/ou responsável para a feitura das fotografias.

b) Escolha do maior número de residências para fotografar.

c) Produção do maior número de fotos possível, mas com boa qualidade.

d) Escolha do melhor ângulo (lembre-se: é o seu olhar, a sua perspectiva)

60 - Trabalho de entrevistas:

a) Data de construção (se possível, de início e término)

b) Nome do primeiro proprietário e dos demais, até o atual.

c) Endereço (se houve alguma mudança ao longo do tempo, também).

d) Se houve alguém responsável pela construção (como encarregado de obras, pedreiro etc.).

e) Origem dos materiais usados na construção (se foram empregados materiais trazidos de outras cidades, estados e/ou países).

f) Características arquitetônicas. 
os alunos conversariam com os proprietários e, tendo permissão, fariam as fotografias das partes externa e interna, não apenas da construção, mas do mobiliário; segunda, de posse de um questionário, entrevistariam os moradores para levantar informações sobre a casa, proprietários antigos e recentes, sobre o mobiliário, sobre a construção do imóvel, sua utilidade quando foi construída e atualmente, entre outras questões; terceira, a produção de um texto contendo as fotografias dos imóveis e mobiliários, bem como os resultados das entrevistas; quarta etapa, seminário para socialização das informações obtidas nas entrevistas e das fotografias; a quinta etapa é a exposição das fotos em espaço reservado na biblioteca do campus.

As ruas nas quais o trabalho foi desenvolvido foram estas: Pinheiro Jr., Tupinambás e Alziro Viana, Dr. Deolindo, Moreira, Timbó, Basílio Pimenta, Barão de Itapemirim, Vinte e Cinco de Março e Dona Joana, Cel. Antônio Marins, Cel. Francisco Braga e Quintiliano de Azevedo e Braz Vivaz' sendo fotografadas, ao todo, 18 casas, além das entrevistas com os moradores. A tabela a seguir traz informações sobre os proprietários, o endereço e a data dos imóveis.

\begin{tabular}{|l|l|l|c|}
\hline Proprietário & \multicolumn{1}{|c|}{ Rua/Avenida } & \multicolumn{1}{c|}{ Bairro } & \multicolumn{1}{c|}{$\begin{array}{c}\text { Ano da } \\
\text { construção }\end{array}$} \\
\hline $\begin{array}{l}\text { Renato } \\
\text { Tanure }\end{array}$ & $\begin{array}{l}\text { Rua Pinheiro Jr. (número não } \\
\text { informado) }\end{array}$ & Ferroviários & 1926 \\
\hline $\begin{array}{l}\text { Mônica } \\
\text { Neves } \\
\text { Angelo }\end{array}$ & Rua Tupinambás, 27 & Aquidabã & 1963 \\
\hline $\begin{array}{l}\text { Joaquim } \\
\begin{array}{l}\text { Francisco de } \\
\text { Morais }\end{array}\end{array}$ & Rua Alziro Viana, 70 & Aquidabã & 1939 \\
\hline Dona Erly & Rua Pinheiro Jr., 89 & Ibitiquara & 1938 \\
\hline
\end{tabular}

g) Dados da mobília (se preserva o antigo mobiliário, sua origem, data possível etc.)

h) Utilidade original e atual do imóvel (se residência, comércio etc.)

i) Estado de conservação atual.

j) Gravação e/ou filmagem da entrevista.

k) Outros aspectos que julgar necessários, como, por exemplo, se há documentos da(s) casa(s) ou da(s) família (s).

70 - Revelação das fotos e organização da entrevista para a produção de texto científico.

80- Organização de um mural para exposição no final do semestre e apresentação dos resultados.

3 De acordo com a proprietária, a data de construção do imóvel é muito anterior ao ano de 1963 , data que consta na escritura. Entretanto, ela não soube precisar quando ela foi construída. Entrevista cedida a Marcelo Rodrigues Baiense, Maycon Lino de Almeida Figueiredo e Raquel Gomes Bósio em maio de 1912. 


\begin{tabular}{|c|c|c|c|}
\hline $\begin{array}{l}\text { Aluízio Vidal } \\
\text { Vantil }\end{array}$ & Rua Dr. Deolindo, 191 & Baiminas & 1926 \\
\hline \begin{tabular}{l|} 
Senhora \\
Stella $^{4}$
\end{tabular} & $\begin{array}{l}\text { Rua Barão de Itapemirim } \\
\text { (número não informado) }\end{array}$ & Centro & 1943 \\
\hline $\begin{array}{l}\text { Proprietário } \\
\text { não } \\
\text { informado } 5\end{array}$ & $\begin{array}{l}\text { Rua Moreira (número não } \\
\text { informado) }\end{array}$ & $\begin{array}{l}\text { Coronel } \\
\text { Borges }\end{array}$ & 1932 \\
\hline $\begin{array}{l}\text { Sebastião } \\
\text { Amaral }\end{array}$ & $\begin{array}{l}\text { Rua Timbó (número não } \\
\text { informado) }\end{array}$ & Amaral & 1929 \\
\hline $\begin{array}{l}\text { Lordegário } \\
\text { da Silva } \\
\text { Monteiro }^{6}\end{array}$ & $\begin{array}{l}\text { Divisa das ruas Coronel } \\
\text { Lincon Vieira de Resende e } \\
\text { José Mancini }\end{array}$ & Amaral & 1955 \\
\hline $\begin{array}{l}\text { Maria de } \\
\text { Ivete } \\
\text { Almeida } \\
\text { Vivaz }\end{array}$ & Rua Braz Vivaz, 02 & Ilha da Luz & 1924 \\
\hline $\begin{array}{l}\text { Família } \\
\text { Borsoi }\end{array}$ & Rua Dona Joana, 18 & Centro & 1916 \\
\hline $\begin{array}{l}\text { Proprietário } \\
\text { não } \\
\text { informado }\end{array}$ & Rua Basílio Pimenta, 25 & Basileia & 1924 \\
\hline $\begin{array}{l}\text { Proprietário } \\
\text { não } \\
\text { informado } 7\end{array}$ & $\begin{array}{l}\text { Rua Coronel Francisco Braga } \\
\text { (número não informado) }\end{array}$ & Guandu & $\begin{array}{l}\text { Por volta de } \\
1910-1920\end{array}$ \\
\hline $\begin{array}{l}\text { Proprietário } \\
\text { não } \\
\text { informado }\end{array}$ & $\begin{array}{l}\text { Rua Coronel Francisco Braga, } \\
23\end{array}$ & Guandu & 1920 \\
\hline $\begin{array}{l}\text { Proprietário } \\
\text { não } \\
\text { informado } 9\end{array}$ & $\begin{array}{l}\text { Rua Coronel Francisco Braga, } \\
03\end{array}$ & Guandu & $\begin{array}{l}\text { Por volta de } \\
1910-1920\end{array}$ \\
\hline
\end{tabular}

4 Segundo a entrevistada, seu pai, Gil Moreira, comprou a casa em 1943, mas a data de construção é muito anterior à informada, que ela não soube informar com precisão. Entrevista cedida a Saulo Calazans e Gebram Emílio Costa Oliveira em maio de 1912.

5 O imóvel era um clube de remo da cidade, o Yole Clube. O entrevistado é um dos fundadores do Clube, o Sr. Almachio Dessaune. (Confirmar) Saulo Calazans e Gebram Emílio Costa Oliveira, em maio de 1912.

6 Segundo entrevista, a casa começou a ser construída em 1945 e só foi terminada dez anos depois, em 1955. Entrevista cedida a Saulo Calazans e Gebram Emílio Costa Oliveira em maio de 1912.

7 Entrevista com o Sr. José Solene de Souza, proprietário do Armarinho Solene, instalado na região há 32 anos. Entrevista cedia a Felipe Gonçalves Vieira, Luan Tofano Elias e Lucas Pastro Guimarães, em maio de 2012.

8 A entrevista foi com o Sr. Aquiles, proprietário da Casas Mota, localizada na mesma região há décadas. Entrevista cedia a Felipe Gonçalves Vieira, Luan Tofano Elias e Lucas Pastro Guimarães, em maio de 2012.

9 Entrevista com o Sr. José Solene de Souza, proprietário do Armarinho Solene, instalado na região há 32 anos. Entrevista cedia a Felipe Gonçalves Vieira, Luan Tofano Elias e Lucas Pastro Guimarães, em maio de 2012. 


\begin{tabular}{|l|l|l|l|}
$\begin{array}{l}\text { Adalton } \\
\text { Moulin }\end{array}$ & $\begin{array}{l}\text { Rua Quintiliano de Azevedo } \\
\text { (número não informado) }\end{array}$ & Guandu & $\begin{array}{l}\text { Por volta de } \\
1930-1940\end{array}$ \\
\hline $\begin{array}{l}\text { Graça Maria } \\
\text { Moreira }\end{array}$ & $\begin{array}{l}\text { Rua 25 de Março (número não } \\
\text { informado) }\end{array}$ & Centro & 1929 \\
\hline $\begin{array}{l}\text { Dona } \\
\text { Manoelina }\end{array}$ & $\begin{array}{l}\text { Rua Coronel Antônio Marins, } \\
24\end{array}$ & Recanto & 1933 \\
\hline
\end{tabular}

Tabela 1: Fonte: Os dados foram compilados das entrevistas concedidas aos alunos do $3^{\circ}$ e do $5^{\circ}$ períodos do curso de História do Centro Universitário São Camilo - Espírito Santo, em maio de 2012.

Uma análise dos dados coletados nas entrevistas monstra que, das dezoito casas elencadas, as mais antigas datam de 1910 e localizam-se no bairro Guandu, mas seus proprietários não foram encontrados para a entrevista. Assim, as datas variam entre 1910 e 1920, mas, provavelmente, são anteriores a esse período. Segundo o Sr. José Solene de Souza, proprietário do Armarinho Solene, instalado na região há 32 anos, em entrevista cedia a Felipe Gonçalves Vieira, Luan Tofano Elias e Lucas Pastro Guimarães, o imóvel que hoje abriga o Restaurante Casteglione, localizado na rua Coronel Francisco Braga, 03, pode ser de mais ou menos 1890. Já o mais recente, datado de 1963, localizado no bairro Aquidabã, também é bem anterior. De acordo com Mônica Neves Angelo, a proprietária atual, a data de construção do imóvel é muito anterior a 1963, mas não soube precisar quando.

A década de 1920 destaca-se como a que tem um maior número de imóveis construídos, sete ao todo, seguida da década de 1930, com cinco, depois a de 1910, com três, e 1940, 1950 e 1960, cada uma com uma casa construída. Em relação à localização dos imóveis, os bairros Guandu (quatro) e centro (três) aparecem como os que abrigam o maior número de casas antigas, seguidos dos bairros Aquidabã e Amaral (dois). Isso se justifica pelo fato de eles terem sido os bairros mais antigos de Cachoeiro, bem como por despontarem como importantes pontos comerciais da cidade nos quais se estabeleceram - e ainda se estabelecem - intensas relações de sociabilidade por causa do fluxo de pessoas de várias regiões e classes sociais que inter-relacionam. Além disso, apesar das transformações econômicas e arquitetônicas pelas quais a cidade vem passando ao longo do tempo, o centro e o Guandu são os bairros que mais

10 Entrevista com Sérgio, genro do proprietário. Entrevista cedida a Felipe Gonçalves Vieira, Luan Tofano Elias e Lucas Pastro Guimarães em maio de 2012. 
preservam seus casarios antigos, o que se verifica à medida que se caminha pela cidade.

Sobre a utilização atual dos imóveis, a maior parte é de uso residencial: onze $^{11}$; cinco são pontos comerciais ${ }^{12}$; um dos imóveis foi demolido ${ }^{13}$ e, hoje, é apenas um terreno; outro está abandonado e em processo de demolição pela ação do tempo ${ }^{14}$. Tal fato merece destaque porque reflete a importância do centro e adjacências para o desenvolvimento comercial da cidade, uma vez que a região central ainda concentra a maior parte do comércio da cidade, apesar de essa atividade econômica ter sido pulverizada, do ponto de vista geográfico, com o correr do tempo.

O uso residencial dos imóveis do centro, por exemplo, conserva uma característica marcante do período em que eles foram construídos: o status. Isso porque apenas os que tinham alguma posição econômica privilegiada moravam no centro da cidade ou nas proximidades, porque era - e ainda é - símbolo de poder, e suas casas, hoje, podem ter se transformado em monumento e, para Le Goff (1990, p. 462) "O monumento tem como características o ligar-se ao poder de perpetuação, voluntária ou involuntária, das sociedades históricas (é um legado à memória coletiva) e o reenviar a testemunhos que só numa parcela mínima são testemunhos escritos".

\footnotetext{
${ }^{11}$ São eles o de propriedade de: Renato Tanure, Mônica Neves Angelo, Joaquim Francisco de Morais, Dona Erly, Aluízio Vidal Vantil, Sebastião Amaral, Lordegário da Silva Monteiro, Maria de Ivete Almeida Vivaz, Família Borsoi, Graça Maria Moreira, Dona Manoelina. O imóvel do Sr. Lordegário da Silva Monteiro está em estado de demolição e abandono.

12 São eles: o de propriedade da Senhora Stella, localizado na rua Barão de Itapemirim, no centro; do Sr. Adalton Moulin, localizado na rua Quintiliano de Azevedo, bairro Guandu; os outros três imóveis estão localizados na rua Coronel Francisco Braga, no bairro Guandu.

13 Localizado na rua Basílio Pimenta, 25, bairro Basileia.

14 O Yole Clube, localizado na rua Moreira, bairro Coronel Borges.
} 


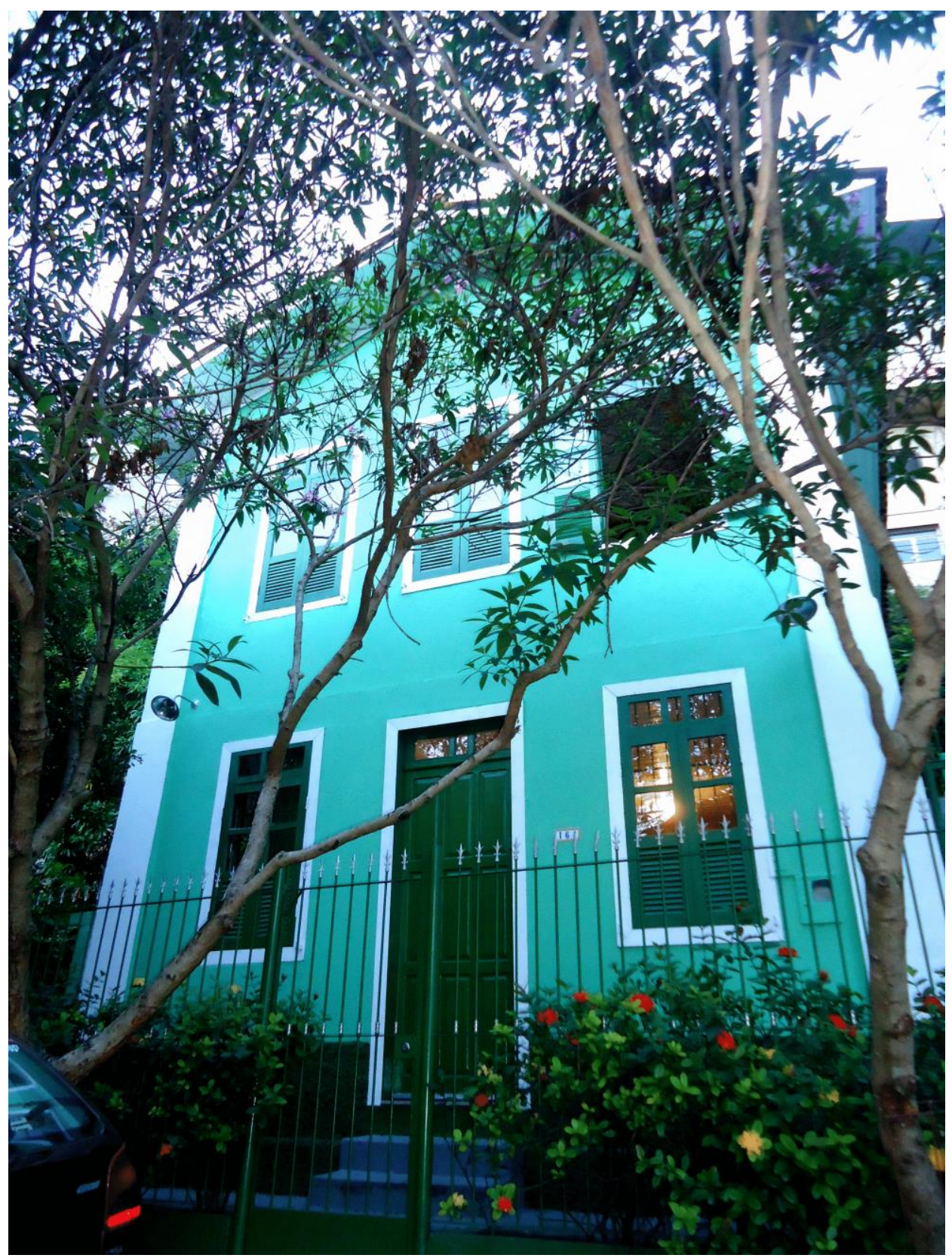

Foto 1: Residência da Sra. Graça Maria Moreira, localizada na 25 de Março, Centro. Ano de construção: 1929

O imóvel localizado na rua Basílio Pimenta, 25, no bairro Basileia, era bastante conhecido por tratar-se de um prostíbulo denominado "Paulinho Vela Acesa" ou "Castelo de Grayskull"15. Recentemente, o prédio foi demolido. A região em que está localizado destacava-se por ser uma área com diversos pontos de prostituição.

15 O nome refere-se à arquitetura e às condições precárias da estrutura do prédio. 
Segundo informações de moradores da redondeza, durante anos (não precisos) funcionou ali um prostíbulo, conhecido popularmente como "Paulinho Vela Acesa" (possível antigo proprietário) ou "Castelo de Grayskull". Atualmente, no andar de baixo, está instalado um pequeno bar que, ultimamente, não vem funcionando com frequência ${ }^{16}$.

$\mathrm{Na}$ região do Guandu, o que as entrevistas revelaram diz respeito à presença de famílias sírio-libanesas que, proprietárias de diversos imóveis, controlavam o comércio da região. Segundo um dos entrevistados, Sr. Solene, proprietário de um armarinho na região sobre imóvel localizado na rua Coronel Francisco Braga, (...) a primeira família a ter a propriedade do imóvel foi a dos sírio-libaneses Tanuri (Tanure), cujo primeiro dono fora o senhor Félix Abdo Tanuri, que instalou embaixo do imóvel um armazém de ferragens. Posteriormente, o imóvel foi sendo passado como herança (...). O Sr. Aquiles, outro entrevistado sobre o Hotel Coelho, na mesma rua, disse que "(...) várias famílias foram proprietárias da residência, incluindo a família Abdala e os senhores José Costa e Isaías Amir Kadi, este último de origem turca. Sob o domínio da família Kadi (Cade), antes do Hotel Coelho, havia um armazém denominado "Armazém do Isaías"17.

Sobre o imóvel localizado na Ilha da Luz, na rua Braz Vivaz, 02, vale ressaltar que ele pertence à família de um importante político de Cachoeiro, o Coronel Anísio Vieira de Almeida Ramos, proveniente de famílias que compuseram a oligarquia capixaba na Primeira República, os Vieira Machado e Almeida Ramos. Essas famílias destacaram-se por exercerem diversos cargos políticos, além de serem grandes proprietários de terra na região de Cachoeiro de Itapemirim e Castelo (Santos, 2012). Segundo informações das entrevistadas, a Sr. Maria de Ivete Almeida Vivaz e sua filha, Antônia Maria Vivaz, filha e neta, respectivamente, de Anísio Ramos, a fazenda Cachoeira Grande, de propriedade do Anísio, "[...] garantiu os materiais para a produção dos tijolos, da areia, da cal, da brita e da madeira para o piso e até mesmo para alguns móveis da casa ${ }^{18 " .}$ Além do mobiliário antigo da casa, os entrevistadores tiveram acesso ao

16 Entrevista feita por Felipe Gonçalves Vieira, Luan Tofano Elias e Lucas Pastro Guimarães, em 07 de maio de 2012.

17 Entrevista cedida pelos senhores Solene e Aquiles, respectivamente a Felipe Gonçalves Vieira, Luan Tofano Elias e Lucas Pastro Guimarães, em 07 de maio de 2012.

18 Entrevista cedida a Naiani Tavares de Mello e Ênio Louro de Moraes Filho em maio de 2012. 
diploma de graduação em Direito do proprietário, adquirido na Faculdade Livre de Jurídicas e Sociais do Rio de Janeiro, documento que reforça uma característica marcante das oligarquias dominantes durante a Primeira República: o bacharelismo em Direito (CARONE, 1974).

Do imóvel localizado na rua Pinheiro Jr., de propriedade do Sr. Renato Tanure, outro indivíduo de origem sírio-libanesa, ele "[...] conserva toda estrutura da casa e móveis antigos guardados em seu interior, como: guardaroupas com mais de cem anos de fabricação, estantes, cristaleiras, um rádio, uma vitrola, um sofá e cadeiras de madeira e aço"19. Nos quartos, há ainda pratos cujas pinturas foram feitas pela irmã do entrevistado, além de filtro de água e relógio antigos, e a varanda tem azulejos franceses.

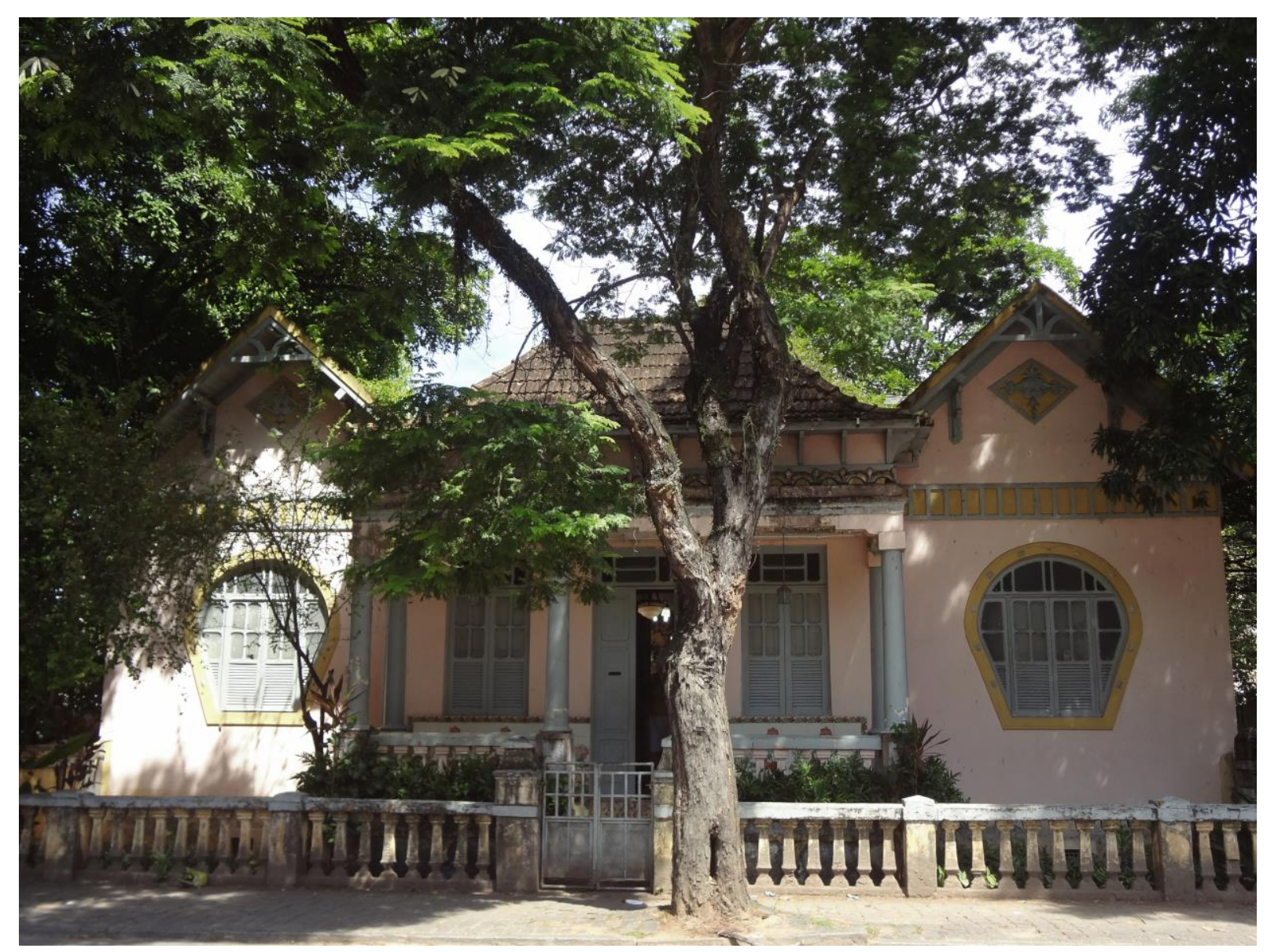

Foto 2: Casa do Sr. Renato Tanure localizada na rua Pinheiro Jr, Bairro Ferroviários. Ano da construção: 1926.

19 Entrevista cedida por Renato Tanure a Cleidiane Amorim, Izabella Quinta da Silva e Luma Karla Schulz Santos em maio de 2012. 
Sobre a casa do Sr. Lordegário da Silva Monteiro, situada na divisa das ruas Coronel Lincon Vieira de Resende e José Mancini, no bairro Amaral, o que chama a atenção é a forma artesanal com que ela foi feita: "[...] areia retirada do rio, brita feita em casa, tijolos comprados em olaria, madeira retirada da mata de alguns amigos $20 "$, provavelmente por causa das dificuldades financeiras para o acesso a esses materiais.

Da residência localizada na rua Tupinambás, 27, no bairro Aquidabã, a Sra. Mônica Neves Angelo ${ }^{21}$ informou que "[...] as casas de antigamente não tinham o lavabo dentro do banheiro: ficava localizado próximo ao banheiro, em uma saleta, do lado de fora". Essa entrevista trouxe duas outras informações importantes: uma sobre a questão religiosa e devocional da família; outra, sobre a posse da escritura do imóvel. Sobre o primeiro

Na frente da casa existe um azulejo com a figura de uma santa. Perguntada sobre o significado daquela imagem, fixada na fachada da casa, a entrevistada disse que sua avó, Judith Conceição, era devota de Santa Imaculada Conceição e que, por isso, logo após efetuado o negócio, tratou de homenagear a santa de sua devoção.

Essa informação é importante porque reflete características da vida privada de uma família que acabou sendo exteriorizada. Também porque reforça tanto o imaginário da proteção divina da casa e da família, expressa na exteriorização de uma devoção, quanto questões identitárias considerando um aspecto devocional. Sobre a escritura, dois aspectos são importantes: primeiro, só essa residência apresentou esse documento, e uma das razões é que, em Cachoeiro, como em muitas cidades brasileiras, a legalização da posse de imóveis é muito difícil; segundo, por uma questão mais técnica, um documento escrito é muito importante para confrontar as informações obtidas por meio da história oral.

Sobre a residência do Sr. Joaquim Francisco de Moraes, na rua Alziro Viana, 70, no bairro Aquidabã, o que se pode destacar é que o morador apresentou uma fotografia do bairro, do início dos anos 1960, em que é possível verificar, analisando a situação de hoje, as importantes transformações pelas

\footnotetext{
20 Entrevista feita por Saulo Calazans e Gebram Emílio Costa Oliveira em maio de 1912.

21 Entrevista cedida a Marcelo Rodrigues Baiense, Maycon Lino Figueiredo e Raquel Gomes Bósio em maio de 1912.
} 
quais o bairro e sua rua passaram ao longo do tempo. Já a respeito da casa de Dona Erly, na rua Pinheiro Jr., 89, no bairro Ibitiquara, apurou-se que o "[...] mobiliário do imóvel, em grande parte, é composto por peças de madeira dos anos 40 do século passado. [...] Desde que foi construída, a casa jamais foi pintada. Portanto, a cor ainda é a original da época de construção22".

Entre as dificuldades encontradas para a realização do trabalho, destacase a negativa das pessoas entrevistadas, desconfiadas de que a entrevista visava ao tombamento do imóvel. Para eles, o tombamento representa um problema porque, a partir desse processo, são impedidos de, por exemplo, reformar o imóvel e até de alugá-lo. Por isso, várias pessoas recusaram-se a conceder entrevistas e houve casos de alguns que permitiam a foto, mas não concediam entrevista. Isso depois de os alunos, reiteradas vezes, dizerem que se tratava de um trabalho acadêmico. O Sr. Jefferson Carlos Agrizzi, morador da casa localizada na rua Dona Joana, 18, no centro da cidade, revelou que "[...] sua família tem grande receio de revelar certos detalhes da casa temendo que 0 governo tombe como patrimônio histórico ${ }^{23 " .}$

\section{Sobre a importância do trabalho para os alunos}

Ao término da atividade, perguntados sobre se essa atividade teve algum significado para sua formação acadêmica, os entrevistados ${ }^{24}$ foram enfáticos ao afirmarem a importância que ela teve para eles, tanto pelos detalhes a que tiveram acesso, quanto pela aplicação prática de conteúdos e conceitos trabalhados em sala de aula, no cotidiano. Cleidiane da Costa Amorim Colli, por exemplo, afirmou que

Participar da atividade "Olhares Sobre a Cidade" teve grande significado para minha formação acadêmica, pois foi através dela que pude pesquisar sobre alguns aspectos da formação da minha cidade e perceber que, como educadora, preciso ter esse cuidado

\footnotetext{
22 Entrevista cedida a Marcelo Rodrigues Baiense, Maycon Lino Figueiredo e Raquel Gomes Bósio em maio de 1912.

23 Entrevista cedida a Naiani Tavares de Mello e Ênio Louro de Moraes Filho em maio de 2012.

24 Por amostragem, entrevistei, entre os dias 19 e 30 de agosto de 2014, sete alunos participantes da atividade: Cleidiane da Costa Amorim Colli, Maycon Lino de Almeida Figueiredo, Izabella Quinta da Silva, Luma Karla Schulz, Felipe Gonçalves Vieira, Luan Tofano Elias e Lucas Pastro Guimarães.
} 
com a história local [...]. Saber, por exemplo, que o azulejo da varanda de uma casa construída em 1950 foi importado da França deixa claro como a cultura europeia influenciava na época em que essas casas foram construídas.

Outro entrevistado, Lucas Pastro Guimarães respondeu: "Essa atividade foi fundamental para a minha formação acadêmica. Em um momento em que nossa cidade estava carente de registros e estudos históricos científicos, fomos a campo [...] para, assim, darmos mais significados para os edifícios/monumentos de nossa cidade, que, na proposta da Nova História, são riquíssimas fontes de pesquisa". Maycon Lino de Almeida Figueiredo disse que a "[...] atividade deu oportunidades para um contato vital com um dos postulados do ofício historiográfico: a pesquisa de campo. Logo, redirecionou as bases teóricas de sala de aula para a prática investigativa".

Já para Luan Tofano Elias, a atividade possibilitou refletir a respeito de "[...] diferentes aspectos, tais como: a vivência do ofício do historiador, levando em conta a pesquisa de campo, os registros documentais escritos, orais e visuais, a aplicação do "faro do historiador" [...], a análise de fontes históricas primárias $[\ldots]^{\prime \prime}$.

Interrogado sobre se, na atuação como professor de História, a atividade "Olhares sobre a Cidade" trouxe alguma contribuição para seu fazer pedagógico, Luan Tofano Elias afirmou:

No meu ofício como professor de História, a pesquisa "Olhares Sobre a Cidade" contribuiu no sentido de "temperar a aula", trazendo curiosidades, vivências, experiências e abstrações aos alunos, fazendo-os compreender melhor o conteúdo e a disciplina como um todo. Trocando em miúdos, a atividade foi um pontapé inicial para que, por meio da contribuição didático-metodológica conseguida através da pesquisa, o aluno consiga enxergar-se imerso na história e compreender que, ao contrário do que se imagina, ela está muito próxima de nós.

Lucas Pastro Guimarães destacou:

Nas aulas de História, dou bastante relevância para os casarios antigos de Cachoeiro de Itapemirim, principalmente quando falamos do início do século XX (época em que a maioria das casas catalogadas foram edificadas), para a importância da cidade no sistema cafeeiro, formação e expansão da cidade de Cachoeiro de 
Itapemirim etc. Ainda na minha atuação como professor de Geografia, dou ênfase à herança da História na formação atual do espaço geográfico da cidade, mostro imagens da época, a relevância econômica da região, etc.

Felipe Gonçalves Vieira, outro aluno entrevistado, destacou que o trabalho pode possibilitar a construção da história local dentro da sala de aula, bem como a inclusão do aluno como agente histórico e de análise da micro-história. Izabella Quinta da Silva ressaltou que esse trabalho possibilita a valorização da história de cada um e da história local que, segundo ela, "[...] passa despercebida ao seguir o currículo e o livro didático". Luma Karla Schulz Santos destacou que, a partir dessa atividade, passou a fazer ligações entre a micro e a macro-história.

Não obstante isso, os entrevistados foram perguntados sobre os conceitos históricos que puderam e podem ser trabalhados com essa atividade. Os que mais constaram nas respostas foram: fonte histórica, cultura material e imaterial, memória individual e coletiva, história regional e local, história oral.

\section{Considerações finais}

Como já foi dito, uma primeira consideração que precisa ser feita é a de que a percepção dos imóveis e de seu interior como fonte histórica foi bastante verificado ao longo da pesquisa. Isso mudou também a visão dos alunos envolvidos, porque puderam perscrutar o cotidiano dos moradores, interagindo com eles, levantando informações privilegiadas sobre a vida privada desses moradores e proprietários. Ao levarem a proposta de trabalho a sério, puderam ter ampliada sua visão a respeito das fontes.

Outro aspecto que vale a pena ressaltar diz respeito à memória, porque, partindo de demandas do presente, ela pôde ser construída e reconstruída em um processo que relacionou fonte material - a casa, seu mobiliário e os objetos do interior - e a história oral, trazendo à luz diversos aspectos do cotidiano dos moradores no presente e no passado.

Além de questões da vida privada, entrevistar os moradores propiciou uma visão importante das transformações pelas quais Cachoeiro de Itapemirim passou. Mostrou, por exemplo, a localização geográfica de parte da colônia sírio 
e libanesa em Cachoeiro e revelou diversos aspectos da vida privada e pública dos moradores, fossem políticos destacados da Primeira República, no Espírito Santo, fossem indivíduos que, embora não estivessem ligados à vida política cachoeirense e capixaba, contribuíram para a construção da história dessa cidade por meio do trabalho.

Além disso, é importante ressaltar que "o trabalho de campo, "[...] ao possibilitar a leitura mais atenta do universo cultural dos estudantes, abre oportunidade para que eles identifiquem componentes dos vários tempos de sua construção, participando, assim, da relação dialógica entre a situação atual do local ou da região e seu passado"(MARTINS, 2009, p.148). Isso pode levá-los a problematizar a identidade desses estudantes, "[...] fazendo-os refletir sobre o legado do passado, o que dele desejam conservar, transformar ou simplesmente abandonar" (MARTINS, 2009, p.148).

\section{Referências}

BERUTTI, F.; MARQUES, A. Ensinar e aprender História. Belo Horizonte: RHJ, 2009.

BITTENCOURT, C. M. F. Ensino de História: fundamentos e métodos. 3. Ed. São Paulo: Cortez, 2009.

CARONE, E. A República Velha: instituições e classes sociais. 3.ed. São Paulo: Difel, 1975.

FONSECA, S. G. Fazer e ensinar História. Belo Horizonte: Dimensão, 2009.

LE GOFF, J. História e Memória. Campinas-SP.: Unicamp, 1990.

MARTINS, M. L. História regional. In: PINSKI, Carla B. (Org.). Novos temas nas aulas de História. São Paulo: Contexto, 2009, 135-152.

MENESES, U. T. B. A memória, cativa da História? Para um mapeamento da memória no campo das Ciências Sociais. Disponível em <http://200.144.255.123/Imagens/Revista/REV034/Media/REV34-01.pdf > Acesso em 05/05/2014.

PERROT, M. Maneiras de Morar. In: PERROT, M. (Org.). História da Vida Privada: da Revolução Francesa à Primeira Guerra. Vol.4. São Paulo: Companhia das Letras, 1991, p. 307-323. 
SANTOS, A. S. Bernardo Horta de Araújo e a política de Cachoeiro de Itapemirim (1887-1913). Cachoeiro de Itapemirim: Cachoeiro Cult, 2012.

Recebido em 23 de janeiro de 2015. Aprovado em 11 de dezembro de 2015 